\title{
Podocyte specific knock out of selenoproteins does not enhance nephropathy in streptozotocin diabetic C57BL/6 mice Marsha N Blauwkamp ${ }^{1,2}$, Jingcheng Yu${ }^{1}$, MaryLee A Schin ${ }^{3}$, Kathleen A Burke ${ }^{3}$, Marla J Berry ${ }^{4}$, Bradley A Carlson ${ }^{5}$, Frank C Brosius III ${ }^{3}$ and Ronald J Koenig*1,2
}

\author{
Address: ${ }^{1}$ Division of Metabolism, Endocrinology and Diabetes, University of Michigan, Ann Arbor, MI 48109-5678, USA, ${ }^{2}$ Cell and Molecular \\ Biology Graduate Program, University of Michigan, Ann Arbor, MI 48109-5619, USA, 32Division of Nephrology, University of Michigan, Ann \\ Arbor, MI 48109-5676, USA, ${ }^{4}$ Department of Cell and Molecular Biology, University of Hawaii at Manoa, Honolulu, HI 96813, USA and \\ ${ }^{5}$ Molecular Biology of Selenium Section, Laboratory of Cancer Prevention, Center for Cancer Research, National Cancer Institute, National \\ Institutes of Health, Bethesda, MD 20892, USA \\ Email: Marsha N Blauwkamp - mousman@umich.edu; Jingcheng Yu - jingyu@umich.edu; MaryLee A Schin - mschin@umich.edu; \\ Kathleen A Burke - kathleen_burke@brown.edu; Marla J Berry - mberry@ hawaii.edu; Bradley A Carlson - carlsonb@mail.nih.gov; \\ Frank C Brosius - fbrosius@umich.edu; Ronald J Koenig* - rkoenig@umich.edu \\ * Corresponding author
}

Published: 22 July 2008

BMC Nephrology 2008, 9:7 doi:10.1186/147/-2369-9-7
Received: 7 January 2008

Accepted: 22 July 2008

This article is available from: http://www.biomedcentral.com/147/-2369/9/7

(C) 2008 Blauwkamp et al; licensee BioMed Central Ltd.

This is an Open Access article distributed under the terms of the Creative Commons Attribution License (http://creativecommons.org/licenses/by/2.0), which permits unrestricted use, distribution, and reproduction in any medium, provided the original work is properly cited.

\begin{abstract}
Background: Selenoproteins contain selenocysteine $(\mathrm{Sec})$, commonly considered the 2 I $^{\text {st }}$ genetically encoded amino acid. Many selenoproteins, such as the glutathione peroxidases and thioredoxin reductases, protect cells against oxidative stress by functioning as antioxidants and/or through their roles in the maintenance of intracellular redox balance. Since oxidative stress has been implicated in the pathogenesis of diabetic nephropathy, we hypothesized that selenoproteins protect against this complication of diabetes.
\end{abstract}

Methods: C57BL/6 mice that have a podocyte-specific inability to incorporate Sec into proteins (denoted in this paper as PodoTrsp ${ }^{-/}$) and control mice were made diabetic by intraperitoneal injection of streptozotocin, or were injected with vehicle. Blood glucose, body weight, microalbuminuria, glomerular mesangial matrix expansion, and immunohistochemical markers of oxidative stress were assessed.

Results: After 3 and 6 months of diabetes, control and PodoTrsp - $^{-/}$mice had similar levels of blood glucose. There were no differences in urinary albumin/creatinine ratios. Periodic acid-Schiff staining to examine mesangial matrix expansion also demonstrated no difference between control and PodoTrsp $^{-1}$ mice after 6 months of diabetes, and there were no differences in immunohistochemical stainings for nitrotyrosine or $\mathrm{NAD}(\mathrm{P}) \mathrm{H}$ dehydrogenase, quinone $\mathrm{I}$.

Conclusion: Loss of podocyte selenoproteins in streptozotocin diabetic C57BL/6 mice does not lead to increased oxidative stress as assessed by nitrotyrosine and $\mathrm{NAD}(\mathrm{P}) \mathrm{H}$ dehydrogenase, quinone I immunostaining, nor does it lead to worsening nephropathy. 


\section{Background}

Selenium, a trace element, is found in the amino acid selenocysteine ( $\mathrm{Sec}$ ) and is cotranslationally incorporated into the protein polypeptide chain via the codon UGA. Although UGA generally signals translation termination, mRNAs that contain a conserved SECIS element in their 3' untranslated regions are able to decode UGA as Sec [1]. $\mathrm{Sec}$ is synthesized on a unique tRNA [2,3], termed tRNA[Ser]Sec because it is first aminoacylated by serine, which is then converted to selenocysteine. Since this is the only tRNA that supports $\mathrm{Sec}$ incorporation into proteins, the absence of tRNA[Ser]Sec results in protein chain termination instead of Sec incorporation. As discussed below, selenoproteins are enzymes with $\mathrm{Sec}$ in the active site. Therefore, even if a truncated protein lacking Sec is stable, it will not be biologically active. Thus, the absence of tRNA[Ser]Sec results in complete functional selenoprotein deficiency. Whole mouse homozygous deletion of the tRNA[Ser]Sec gene Trsp is embryonic lethal [4]. However, the generation of mice carrying Trsp alleles flanked by loxP sites has allowed the study of organ-specific deletion of selenoprotein synthesis [5].

The human genome encodes 25 selenoproteins and the mouse genome 24 [6]. Many selenoproteins function as antioxidant enzymes or in redox signaling. Examples of selenoproteins with these activities include the glutathione peroxidases (Gpx) and thioredoxin reductases (Trxr) (reviewed in [7]). Other selenoproteins such as selenophosphate synthetase and selenoprotein P indirectly support those activities by functioning in Sec synthesis and selenium transport and storage [7].

Superoxide is a highly reactive and potentially toxic oxidant produced during mitochondrial respiration and by several cytoplasmic enzymes such as NAD $(\mathrm{P}) \mathrm{H}$ oxidase. In diabetes, hyperglycemia induces overproduction of superoxide via the mitochondrial electron transport chain as well as by increased NAD $(\mathrm{P}) \mathrm{H}$ oxidase activity [8] leading to oxidative stress [9]. Oxidative stress is thought to play an important role in the progression of diabetic complications, including nephropathy [10]. Podocyte (glomerular epithelial cell) damage is central to the development of diabetic nephropathy [11]. An increase in glomerular oxidative stress occurs early in diabetic nephropathy and enhanced mitochondrial and cytoplasmic oxidant stress leads directly to apoptosis in podocytes exposed to high extracellular glucose [12]. It has been shown that injury to diabetic kidneys is reduced in transgenic mice that over express superoxide dismutase (SOD1) [13]. In addition, streptozotocin (STZ) diabetic mice developed increased oxidative stress and kidney damage when subjected to a selenium deficient diet [14]. However, a recent study of diabetic Gpx1 homozygous null mice found that Gpx1 was not protective against renal injury [15].

C57BL/6 mice are relatively resistant to the development of diabetic nephropathy [16]. Given the evidence supporting a role of oxidative stress in diabetic nephropathy and the role of selenoproteins in protecting against oxidative stress, we postulated that podocyte selenoproteins protect against the development of diabetic nephropathy in $\mathrm{C} 57 \mathrm{BL} / 6$ mice. To test this hypothesis, we created a podocyte specific knock out of all selenoproteins (PodoTrsp ${ }^{-/}$) in C57BL/6 mice, induced diabetes with STZ, and examined the mice for progression of diabetic nephropathy. Contrary to our hypothesis, we found the PodoTrsp-/mice did not develop increased nephropathy.

\section{Methods Targeted Inactivation of the Selenocysteine tRNA[Ser]Sec gene Trsp in Podocytes}

C57BL/6 transgenic mice expressing Cre recombinase driven by the $2.5 \mathrm{~kb}$ human podocin (NPHS2) promoter were obtained from L.B. Holzman (University of Michigan, Ann Arbor, MI) [17]. The expression of Cre recombinase in these mice does not cause glomerular abnormalities [17-19]. Podocin-Cre mice were mated with C57BL/ 6 mice in which both Trsp alleles are flanked by loxP sites, denoted $\operatorname{Tr} s p^{\mathrm{L} / \mathrm{L}}[5]$. The resulting podocinCre; $\operatorname{Tr} s p^{\mathrm{L} /+}$ mice were mated with $\operatorname{Tr} s p^{\mathrm{L} / \mathrm{L}}$ mice to generate podocin-Cre; $T r s p^{\mathrm{L} / \mathrm{L}}$ mice, denoted in this paper as PodoTrsp ${ }^{-/}$. Littermates of the genotype $\operatorname{Tr} s p^{\mathrm{L} / \mathrm{L}}$ were used as controls. Genotyping was performed by PCR using the following oligonucleotide primers for Trsp: 5'-CAA AAC CTC GCC TCC AAG TGA C-3' and 5'-TGT GAG ACG ACC TTC TAT GCT CG-3'; and for Cre: 5'-GCG GTC TGG CAG TAA AAA CTA TC-3' and 5'-GTG AAA CAG CAT TGC TGT CAC TT-3'. The PCR program used for Trsp detection is as follows: step $1,95^{\circ} \mathrm{C}$ for $5 \mathrm{~min}$; step $2,95^{\circ} \mathrm{C}$ for $15 \mathrm{sec}$; step $3,64^{\circ} \mathrm{C}$ for $30 \mathrm{sec}$; step $4,68^{\circ} \mathrm{C}$ for $2 \mathrm{~min}$; step 5, 30 repetitions of steps 2 to 4 . The PCR program used for Cre detection is as follows: step $1,95^{\circ} \mathrm{C}$ for $5 \mathrm{~min}$; step 2, $94^{\circ} \mathrm{C}$ for $30 \mathrm{sec}$; step $3,51^{\circ} \mathrm{C}$ for $45 \mathrm{sec}$; step $4,72^{\circ} \mathrm{C}$ for $1 \mathrm{~min}$; step 5, 35 repetitions of steps 2 to 4 . All animal care and handling procedures were approved by the University of Michigan Committee on Use and Care of Animals.

\section{Induction of diabetes}

Ten week old male PodoTrsp $\%$ and Trsp $p^{\mathrm{L} / \mathrm{L}}$ (as controls) mice were fasted for 4 hours and then injected intraperitoneally with $50 \mathrm{mg} / \mathrm{kg} \mathrm{STZ} \mathrm{(Sigma)} \mathrm{or} \mathrm{vehicle} \mathrm{for} 5$ consecutive days according to the low dose protocol of the Animal Models of Diabetic Complications Consortium http://www.amdcc.org. STZ was prepared in freshly made $100 \mathrm{mM}$ sodium citrate buffer $\mathrm{pH} 4.5$ at $7.5 \mathrm{mg} / \mathrm{ml}$ and used within 15 minutes. For each experiment, the number of mice used is stated in the figure legend. 


\section{Immunohistology}

Immunoperoxidase staining for Wilms' tumor homolog (Wt1) and Gpx1 was performed on 2\% paraformaldehyde-lysine-periodate (PLP) fixed kidney cryostat consecutive sections $(3 \mu \mathrm{m})$. PLP-fixed tissue sections were incubated for $2 \mathrm{hrs}$ at $90^{\circ} \mathrm{C}$ in Retrieve-All 1 (Covance), followed by 3\% hydrogen peroxide in methanol for 30 mins and $1.5 \%$ normal rabbit serum in 3\% BSA, $0.1 \%$ Tween 20 in $1 \times$ PBS for 20 mins according to Vectastain Elite ABC kits-Goat IgG and Sheep IgG. Sections were then incubated with primary antibodies at $1 \mu \mathrm{g} / \mu \mathrm{l}$ of either goat anti Wt1 polyclonal (1:200) (Santa Cruz) or sheep anti Gpx1 polyclonal $(1: 4,000)$ (Novus Biologicals) for 1 hr at room temperature. After washes in PBS, sections were incubated in biotinylated secondary antibodies (biotinylated anti sheep IgG or biotinylated anti goat IgG) for $1 \mathrm{hr}$ at room temperature, followed by incubation with $\mathrm{ABC}$ reagent for $1 \mathrm{hr}$ at room temperature (Vectastain Elite ABC kits-Sheep IgG and Goat IgG). Sections incubated with anti Wt1 polyclonal antibody were developed using Vector SG (Vector) for 5 mins to produce a gray color and sections incubated with anti Gpx1 polyclonal antibody were developed using Vector NovaRED (Vector) for 5 mins to produce a red color.

To assess oxidative stress, immunoperoxidase staining was performed on PLP fixed, paraffin kidney sections. Consecutive $3 \mu \mathrm{m}$ sections were stained with rabbit anti nitrotyrosine (1:100) (Millipore) or goat anti Wt1 (1:300). As a negative control, the anti nitrotyrosine antibody was preincubated with $25 \mu \mathrm{M}$ nitrotyrosine for 1 hour and $25 \mu \mathrm{M}$ nitrotyrosine also was included during the primary antibody incubation. To assess whether antioxidant enzymes might be induced to compensate for the loss of selenoproteins, consecutive $3 \mu \mathrm{m}$ sections were stained for Wt1 or NAD(P)H dehydrogenase, quinone 1 (NQO1) using rabbit anti NQO1 (1:100) (Abcam). The general procedures for these immunostainings were as described above, except that the sections stained for nitrotyrosine and NQO1 were developed with 3,3'-diaminobenzidine. All immunostainings for nitrotyrosine, as well as all for NQO1 and Wt1, were done at the same time and were photographed under identical conditions. Adobe Photoshop was used to adjust the color of the Wt1 images to facilitate identification of podocytes when the images were merged.

\section{Biochemical Analysis}

Glucose levels in fresh blood obtained between 9 and 10 AM from the tail veins of nonfasted mice were measured once a month by glucometer (Therasense). Urine was collected at 3 and 6 months of diabetes from mice housed in metabolic cages for 4 hrs. Elisa kits-Albuwell $\mathrm{M}$ and Creatinine Companion (Exocell) were used to measure urine levels of albumin and creatinine.

\section{Histology and Morphometry}

PLP-fixed tissue paraffin sections $(3 \mu \mathrm{m})$ were stained with periodic acid-Schiff's (PAS) reagent to identify kidney structure and hematoxylin to visualize cell nuclei. Microscopic images of glomeruli (10 images per sample) were taken at $20 \times$ magnification and used for calculating the mesangial matrix cell volume per glomerular tuft. The mean area of each glomerular tuft was measured by manually tracing the glomerular outline on a computer screen and calculating that area by computerized morphometry using Metamorph 6.1 (Molecular Devices) at a final magnification of $150 \times$. The mesangial matrix cell volume was then quantified by measuring the area of the glomerulus stained pink to purplish red (PAS positive) using Metamorph 6.1. Percent of mesangial matrix was calculated as (area PAS positive/total glomerular tuft area) multiplied by 100 .

\section{Results}

\section{Deletion of selenoproteins in PodoTrsp ${ }^{-/}$podocytes}

To demonstrate the knockout of podocyte selenoproteins, consecutive kidney sections from control and PodoTrsp $/$ mice were immunostained for Wt1 to identify podocytes (Fig. 1A \&1E) and Gpx1 to identify a selenoprotein (Fig. $1 \mathrm{~B} \& 1 \mathrm{~F})$. Gpx1 is ideal for this purpose because, in the absence of Sec incorporation, Gpx1 mRNA is degraded by nonsense mediated decay, so that very little truncated Gpx1 protein (lacking Sec) is made [20,21]. A merge of the Wt1 and Gpx1 immunostainings shows that control

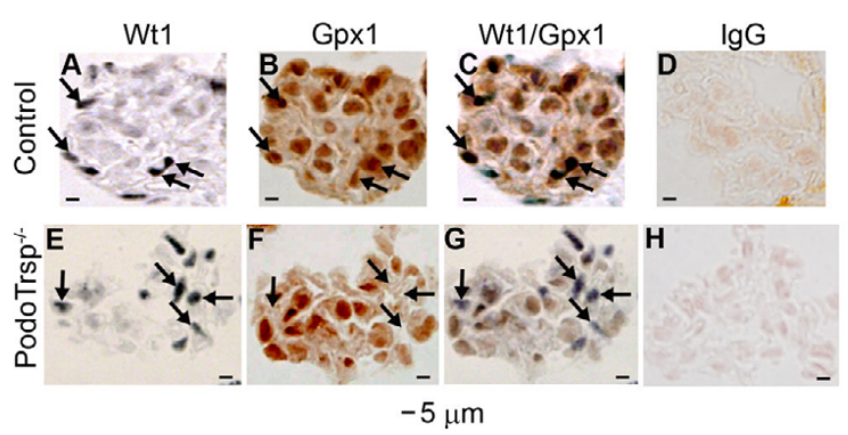

Figure I

Immunoperoxidase staining demonstrating a reduction in podocyte Gpx I expression in PodoTrsp-/-

mice. Consecutive $3 \mu \mathrm{m}$ kidney sections were stained from control $\left(T r s p^{\mathrm{L} / \mathrm{L}}\right)$ mice (A-D) and PodoTrsp ${ }^{-/-}$mice $(\mathrm{E}-\mathrm{H})$. A, E Anti-Wtl antibody staining to identify podocytes (arrows). B, F Anti-GpxI antibody staining (arrows indicate the same cells as in $A, E)$. C, G Merge of WtI and Gpxl sections from A, B and $E, F$, respectively. $C$, Arrows indicate podocytes from control mice express both WtI and Gpxl. G, Arrows indicate podocytes from PodoTrsp ${ }^{-/-}$mice lose GpxI expression. $\mathrm{D}, \mathrm{H}$ stained with normal sheep $\lg \mathrm{G}$ as a negative control for the GpxI antibody. 
mice express Gpx1 in podocytes (Fig. 1C), whereas expression is very low to nil in PodoTrsp-/- podocytes (Fig. 1G).

\section{PodoTrsp-l- and control mice developed similar degrees of hyperglycemia and body weight changes in response to STZ}

STZ diabetes was induced in male PodoTrsp $\mathrm{P}^{-/}$and control mice. The blood glucose levels for STZ treated PodoTrsp-/ - and control mice were similar at 3 and 6 months of diabetes (Fig 2A). STZ treated mice also showed a decrease (means \pm SEM; $\mathrm{P}<0.01$ ) in body weight compared to vehicle treated mice at 3 and 6 months of diabetes (Fig 2B).

PodoTrsp ${ }^{-/-}$mice do not have an increased susceptibility to nephropathy after 6 months of diabetes

Microalbuminuria was assessed to evaluate diabetic renal damage. The albumin to creatinine ratios were not increased in PodoTrsp $/$ - versus control mice after 3 or 6
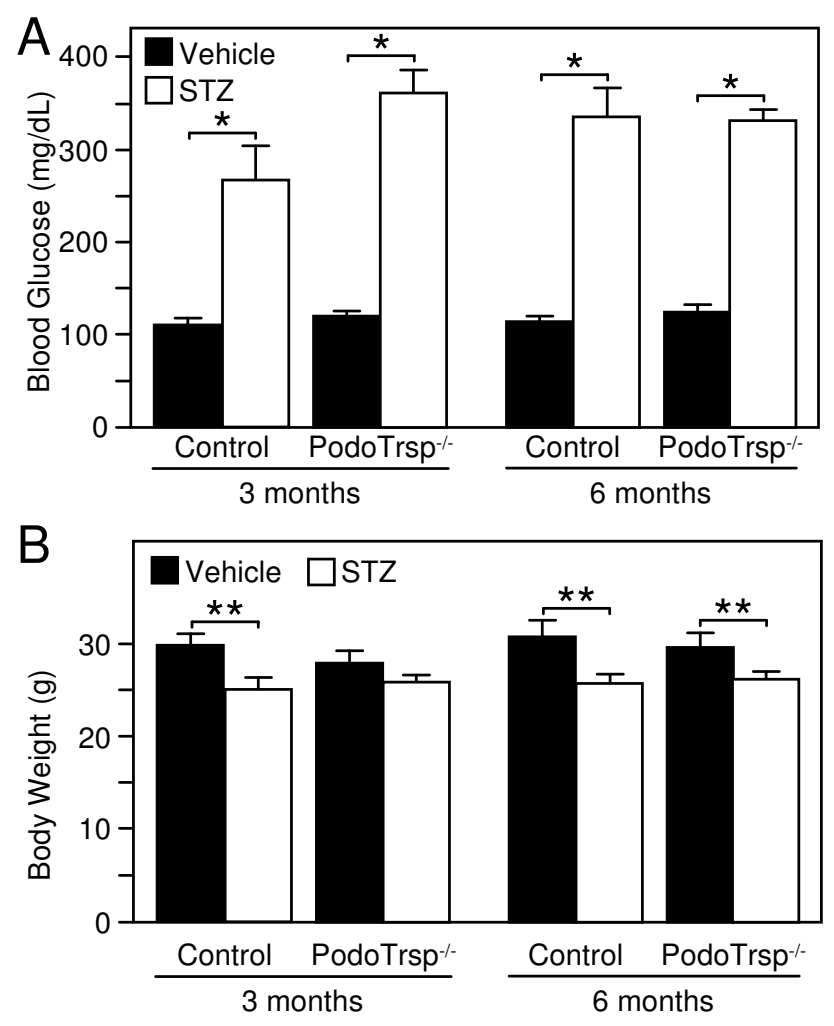

\section{Figure 2}

Blood glucose and body weight in PodoTrsp ${ }^{-/-}$and control (Trsp ${ }^{\mathrm{L} / L}$ ) mice. A, blood glucose levels and B, body weight 3 and 6 months after the onset of STZ-induced diabetes (or after vehicle injection). Control mice, vehicle $n=10$, STZ $n=7$; PodoTrsp $/$ - mice, vehicle $n=13$, STZ $n=12 . P$ values were determined by two-tailed $t$ test. $* \mathrm{P}<0.01$, $* * \mathrm{P}<$ 0.001 . months of diabetes, and in fact were similar to the levels seen in non-diabetic mice (Fig 3). To further explore diabetic nephropathy, mesangial matrix expansion was analyzed. PAS and hematoxylin staining of kidney sections again showed no significant differences between PodoTrsp $\%$ and control mice after 6 months of diabetes (Fig 4).

\section{PodoTrsp ${ }^{-/-}$mice do not have increased glomerular or podocyte oxidative stress after 6 months of diabetes}

Consecutive $3 \mu \mathrm{m}$ kidney sections from control and PodoTrsp $^{-/}$- mice were immunostained for nitrotyrosine as a marker for oxidative stress and for Wt1 to identify podocytes. No differences were observed between the podocytes of PodoTrsp $/$ - and control mice for nitrotyrosine immunostaining (Figure 5). Consecutive $3 \mu \mathrm{m}$ kidney sections also were stained for Wt1 and NQO1 as an antioxidant enzyme that could be induced to compensate for the loss of selenoproteins (Fig 6). Again, no differences were observed between the podocytes of PodoTrsp $/$ - and control mice for NQO1 immunostaining.

\section{Discussion}

Although multiple lines of evidence suggest an important role for oxidative stress in the pathogenesis of diabetic complications including nephropathy [9-14], the precise role of oxidative stress is not known. In addition, there are many endogenous factors that potentially can counteract oxidative stress, and it is not known which of these are most important in protecting against diabetic complications.

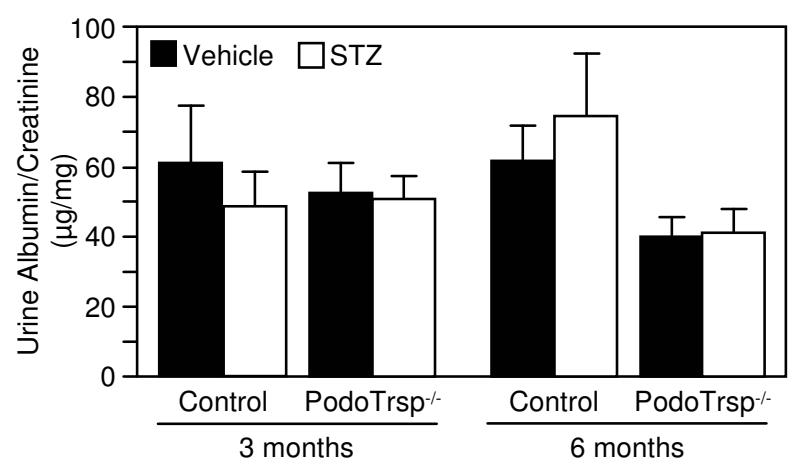

Figure 3

Urinary albumin/creatinine ratios are not increased in PodoTrsp ${ }^{-/-}$versus control $\left(\right.$Trsp $\left.^{\mathrm{L} / L}\right)$ mice. Three months after the onset of diabetes (or after vehicle injection): control mice, vehicle $n=10$, STZ $n=7$; PodoTrsp ${ }^{-1-}$ mice, vehicle $n=12, S T Z n=13$. Six months after the onset of diabetes (or after vehicle injection): control mice, vehicle $n$ $=8, \mathrm{STZ}_{\mathrm{n}}=6$; PodoTrsp ${ }^{-1-}$ mice, vehicle $\mathrm{n}=9, \mathrm{STZ} \mathrm{n}=13$. 


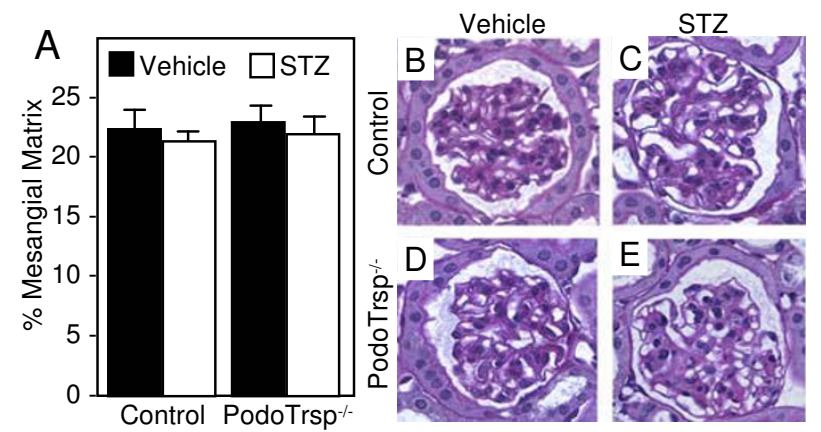

\section{Figure 4}

PodoTrsp ${ }^{-/}$and control (Trsp ${ }^{\mathrm{L} / \mathrm{L}}$ ) mice have similar mesangial matrix volumes. A, Percent of mesangial matrix in glomeruli from control and PodoTrsp ${ }^{-/-}$mice after 6 months of diabetes (or after vehicle injection). Control mice, vehicle $n=6, S T Z n=6$; PodoTrsp ${ }^{-/}$mice, vehicle $n=6, S T Z$ $\mathrm{n}=6$. B-E, PAS staining of glomeruli.

In the diabetic kidney, oxidative stress coincides with podocyte apoptosis [12]; hence, podocyte antioxidant proteins are expected to be important in protecting against diabetic nephropathy. Given the toxicity of uncontrolled oxidative stress, it is likely that substantial redundancy exists in the functions of antioxidant proteins. The majority of selenoproteins with known functions are involved in the management of oxidative stress. This includes four selenoprotein glutathione peroxidases in rodents and three thioredoxin reductases, and likely includes numerous others such as selenoproteins $\mathrm{H}, \mathrm{K}, \mathrm{P}$, $\mathrm{R}, \mathrm{S}$ and $\mathrm{W}$ ([22] and reviewed in [7]). Thus, we hypothesized that selenoproteins as a group protect against diabetic nephropathy, and that deletion of all selenoproteins would reveal their importance by preventing compensatory effects. We tested this hypothesis by deleting the tRNA[Ser]Sec gene Trsp in podocytes of C57BL/ 6 mice. The choice of mouse strain was dictated by the fact that both the podocin-Cre and $\operatorname{Tr} s p^{\mathrm{L} / \mathrm{L}}$ genotypes were on pure C57BL/6 backgrounds. The fact that diabetic C57BL/6 mice are relatively resistant to nephropathy [16] also made this a logical choice, allowing us to test whether selenoproteins at least in part underlie this resistant phenotype.

The loss of podocyte selenoproteins did not result in increased nitrotyrosine staining as a marker for oxidative stress, nor did it enhance the development of diabetic nephropathy as assessed by microalbuminuria and mesangial matrix expansion. Our findings extend those of de Haan et al [15], who showed that deletion of Gpx1 alone did not enhance diabetic nephropathy.

The data suggest that podocyte selenoproteins are not important in the protection against diabetic nephropathy,

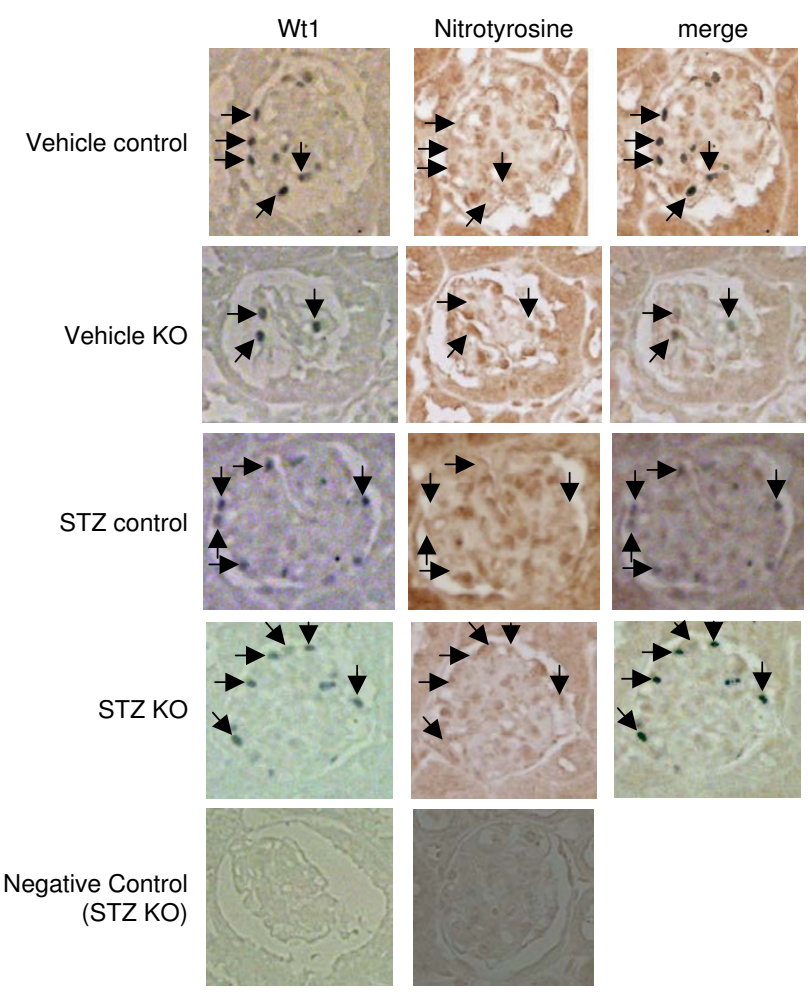

\section{Figure 5}

Immunoperoxidase staining demonstrating similar levels of nitrotyrosine in podocytes of PodoTrsp ${ }^{-/-}$and control (Trsp $\left.{ }^{\mathrm{L} / \mathrm{L}}\right)$ mice. Consecutive $3 \mu \mathrm{m}$ kidney sections from vehicle control, vehicle KO (PodoTrsp ${ }^{-/}$), STZ control, and STZ KO (PodoTrsp--/) mice were stained for nitrotyrosine or $\mathrm{Wtl}$ (to identify podocytes). Arrows indicate selected podocytes in the $\mathrm{WtI}$ and merged images, and indicate the identical positions in the nitrotyrosine images. Negative control staining for WtI utilized normal IgG in place of the primary antibody, and for nitrotyrosine utilized coincubation of the primary antibody with nitrotyrosine.

or that remaining antioxidant mechanisms can compensate. However, we did not find increased expression of the antioxidant enzyme NQO1. Our results may not extend to other mouse strains or to animals with a longer duration or greater severity of diabetes. Additionally, oxidative stress and selenoproteins in glomerular cells other than podocytes may be important in the development and progression of nephropathy.

\section{Conclusion}

The loss of podocyte selenoproteins does not enhance nephropathy or oxidative stress in C57BL/6 mice after 6 months of STZ-induced diabetes. Either podocyte selenoproteins are not important in protecting against diabetic nephropathy, or additional antioxidant proteins compensate for the absence of selenoproteins. As with any model 


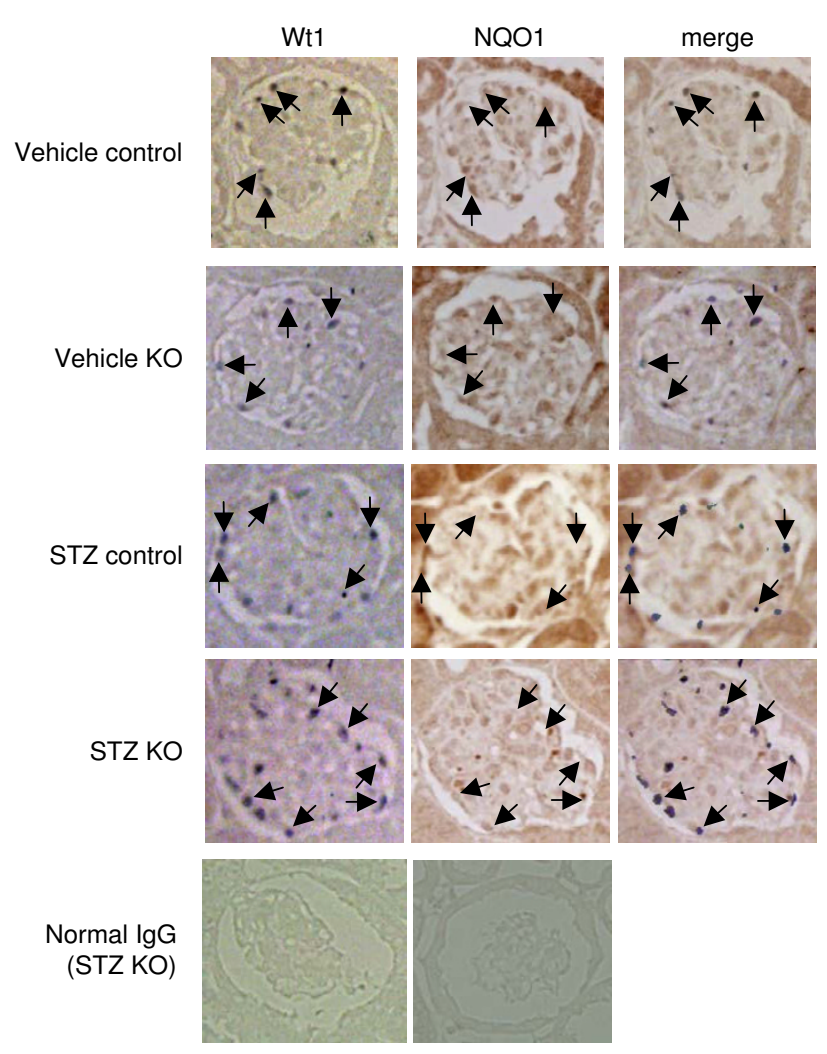

\section{Figure 6}

Immunoperoxidase staining demonstrating similar levels of NQOI in podocytes of PodoTrsp-l- and control (Trsp $\left.{ }^{\mathrm{L} / \mathrm{L}}\right)$ mice. Consecutive $3 \mu \mathrm{m}$ kidney sections from vehicle control, vehicle KO (PodoTrsp $\left.{ }^{-/}\right)$, STZ control, and STZ KO $\left(\right.$ PodoTrsp $\left.^{-/}\right)$mice were stained for NQOI or $\mathrm{WtI}$ (to identify podocytes). Arrows indicate selected podocytes in the $\mathrm{WtI}$ and merged images, and indicate the identical positions in the NQOI images. Incubations with normal $\lg \mathrm{g}$ in place of the primary antibodies served as negative controls.

system, the results may not be transferable to other diabetic models or to diabetic nephropathy in humans.

\section{Competing interests}

The authors declare that they have no competing interests.

\section{Authors' contributions}

MNB participated in the design and execution of all experiments and drafted the manuscript. JY participated in the mouse breeding, genotyping and immunohistochemistry. MAS participated in the analysis of kidney function and histology. KAB participated in mouse breeding, genotyping and induction of diabetes. MJB participated in conception of the study and helped draft the manuscript. BAC participated in conception of the study, generation and breeding of the floxed mice, and helped draft the manu- script. FCB participated in conception and design of the study, data analysis, and helped draft the manuscript. RJK participated in conception and design of the study, data analysis, and helped draft the manuscript. All authors read and approved the final manuscript.

\section{Acknowledgements}

We thank Dr. L. B. Holzman for providing the podocin-Cre mice. This work was supported by a Pilot and Feasibility grant and the Cell and Molecular Biology Core of the Michigan Diabetes Research and Training Center (NIH P60 DK020572).

\section{References}

I. Berry MJ, Banu L, Harney JW, Larsen PR: Functional characterization of the eukaryotic SECIS elements which direct selenocysteine insertion at UGA codons. Embo J 1993, I 2:33 I5-3322.

2. Lee BJ, Worland PJ, Davis JN, Stadtman TC, Hatfield DL: Identifica-

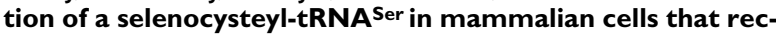
ognizes the nonsense codon, UGA. J Biol Chem 1989, 264:9724-9727.

3. Leinfelder W, Stadtman TC, Bock A: Occurrence in vivo of selenocysteyl-tRNASERUCA in Escherichia coli. Effect of sel mutations. J Biol Chem 1989, 264:9720-9723.

4. Bosl MR, Takaku K, Oshima M, Nishimura S, Taketo MM: Early embryonic lethality caused by targeted disruption of the mouse selenocysteine tRNA gene (Trsp). Proc Natl Acad Sci USA 1997, 94:553।-5534.

5. Kumaraswamy E, Carlson BA, Morgan F, Miyoshi K, Robinson GW, Su D, Wang S, Southon E, Tessarollo L, Lee BJ, Gladyshev VN, Hennighausen L, Hatfield $D L$ : Selective removal of the selenocysteine tRNA[Ser]Sec gene (Trsp) in mouse mammary epithelium. Mol Cell Biol 2003, 23:1477-| 488.

6. Kryukov GV, Castellano S, Novoselov SV, Lobanov AV, Zehtab O, Guigo R, Gladyshev VN: Characterization of mammalian selenoproteomes. Science 2003, 300:|439-| 443.

7. Papp LV, Lu J, Holmgren A, Khanna KK: From selenium to selenoproteins: synthesis, identity, and their role in human health. Antioxid Redox Signal 2007, 9:775-806.

8. Satoh M, Fujimoto S, Haruna Y, Arakawa S, Horike H, Komai N, Sasaki T, Tsujioka K, Makino H, Kashihara N: NAD(P)H oxidase and uncoupled nitric oxide synthase are major sources of glomerular superoxide in rats with experimental diabetic nephropathy. Am J Physiol Renal Physiol 2005, 288:FI I 44-I I 52.

9. Nishikawa T, Edelstein D, Du XL, Yamagishi S, Matsumura T, Kaneda Y, Yorek MA, Beebe D, Oates PJ, Hammes HP, Giardino I, Brownlee $M$ : Normalizing mitochondrial superoxide production blocks three pathways of hyperglycaemic damage. Nature 2000, 404:787-790.

10. $\mathrm{Ha} \mathrm{H}, \mathrm{Kim} \mathrm{KH:} \mathrm{Pathogenesis} \mathrm{of} \mathrm{diabetic} \mathrm{nephropathy:} \mathrm{the} \mathrm{role}$ of oxidative stress and protein kinase C. Diabetes Res Clin Pract 1999, 45:|47-|5|.

II. Pagtalunan ME, Miller PL, Jumping-Eagle S, Nelson RG, Myers BD, Rennke HG, Coplon NS, Sun L, Meyer TW: Podocyte loss and progressive glomerular injury in type II diabetes. J Clin Invest 1997, 99:342-348.

12. Susztak K, Raff AC, Schiffer M, Bottinger EP: Glucose-induced reactive oxygen species cause apoptosis of podocytes and podocyte depletion at the onset of diabetic nephropathy. Diabetes 2006, 55:225-233.

13. Craven PA, Melhem MF, Phillips SL, DeRubertis FR: Overexpression of $\mathrm{Cu}^{2+} / \mathrm{Zn}^{2+}$ superoxide dismutase protects against early diabetic glomerular injury in transgenic mice. Diabetes 200I, 50:2II4-2I25.

14. Reddi AS, Bollineni JS: Selenium-deficient diet induces renal oxidative stress and injury via TGF- $\beta$ I in normal and diabetic rats. Kidney Int 200I, 59:1342-1353.

15. de Haan JB, Stefanovic N, Nikolic-Paterson D, Scurr LL, Croft KD, Mori TA, Hertzog P, Kola I, Atkins RC, Tesch GH: Kidney expression of glutathione peroxidase- $I$ is not protective against streptozotocin-induced diabetic nephropathy. Am J Physiol Renal Physiol 2005, 289:F544-55I. 
16. Qi Z, Fujita H, Jin J, Davis LS, Wang Y, Fogo AB, Breyer MD: Characterization of susceptibility of inbred mouse strains to diabetic nephropathy. Diabetes 2005, 54:2628-2637.

17. Moeller MJ, Sanden SK, Soofi A, Wiggins RC, Holzman LB: Podocyte-specific expression of cre recombinase in transgenic mice. Genesis 2003, 35:39-42.

18. El-Aouni C, Herbach N, Blattner SM, Henger A, Rastaldi MP, Jarad G, Miner JH, Moeller MJ, St-Arnaud R, Dedhar S, Holzman LB, Wanke R, Kretzler M: Podocyte-specific deletion of integrin-linked kinase results in severe glomerular basement membrane alterations and progressive glomerulosclerosis. J Am Soc Nephrol 2006, 17:1334-1344.

19. Suleiman H, Heudobler D, Raschta AS, Zhao Y, Zhao Q, Hertting I, Vitzthum H, Moeller MJ, Holzman LB, Rachel R, Johnson R, Westphal $H$, Rascle $A$, Witzgall $R$ : The podocyte-specific inactivation of $L m x I b, L d b \mid$ and E2a yields new insight into a transcriptional network in podocytes. Dev Biol 2007, 304:70I-7I2.

20. Moriarty PM, Reddy CC, Maquat LE: Selenium deficiency reduces the abundance of mRNA for Se-dependent glutathione peroxidase I by a UGA-dependent mechanism likely to be nonsense codon-mediated decay of cytoplasmic mRNA. Mol Cell Biol 1998, 18:2932-2939.

21. Squires JE, Stoytchev I, Forry EP, Berry MJ: SBP2 binding affinity is a major determinant in differential selenoprotein mRNA translation and sensitivity to nonsense-mediated decay. Mol Cell Biol 2007, 27:7848-7855.

22. Panee J, Stoytcheva ZR, Liu W, Berry MJ: Selenoprotein $\mathbf{H}$ is a redox-sensing high mobility group family DNA-binding protein that up-regulates genes involved in glutathione synthesis and phase II detoxification. I Biol Chem 2007, 282:23759-23765.

\section{Pre-publication history}

The pre-publication history for this paper can be accessed here:

http://www.biomedcentral.com/1471-2369/9/7/prepub

\section{Publish with Biomed Central and every scientist can read your work free of charge}

"BioMed Central will be the most significant development for disseminating the results of biomedical research in our lifetime. "

Sir Paul Nurse, Cancer Research UK

Your research papers will be:

- available free of charge to the entire biomedical community

- peer reviewed and published immediately upon acceptance

- cited in PubMed and archived on PubMed Central

- yours - you keep the copyright 